\title{
CONCEC̄ÕES E PRÁTICAS DE AVALIAÇÃO DA ESCRITA: FORMAÇÃO EM SÃO TOMÉ E PRÍNCIPE!
}

(D) ANA RITA GORGULHO'

(1) NILZA COSTA"

(D) LEONOR SANTOS"I!

Universidade de Aveiro (UA), Aveiro, Portugal; ana.gorgulho@ua.pt

' Universidade de Aveiro (UA), Aveiro, Portugal; nilzacosta@ua.pt

III Universidade de Aveiro (UA), Aveiro, Portugal; Instituto Marquês de Valle Flôr (IMVF), Lisboa, Portugal; mleonor.santos@ese.ipsantarem.pt

\section{RESUMO}

Neste artigo analisam-se conceções e práticas relatadas de 19 professores de Língua Portuguesa em São Tomée Príncipe, como ponto de partida de uma oficina de formação. Numa abordagem qualitativa, privilegiou-se a análise de conteúdo dos dados de diversas fontes (questionário, reflexões em diário de bordo e registos da investigadora). Os principais resultados revelam que o ensino e a avaliação da produção escrita não estão totalmente ausentes das práticas destes professores, mas esta é ocasional e frequentemente não programada, resultando em constrangimentos. Crendo que lacunas de formação dos professores sobre avaliação têm influência nas conceções e práticas, defende-se que a formação contínua, partindo das necessidades dos professores, contribuirá para o seu desenvolvimento profissional.

PALAVRAs-ChAVE AVALIAÇÃO DA APRENDIZAGEM • ESCRITA • SÃO TOMÉ E PRÍNCIPE • AVALIAÇÃO CONTÍNUA.

1 Trabalho desenvolvido no contexto do estudo de doutoramento A avaliação do ensino e aprendizagem da Lingua Portuguesa: para uma cooperação internacional para o desenvolvimento na formação de professores, financiado por fundos nacionais por meio da Fundação para a Ciência e a Tecnologia (FCT), I.P (Referência: $\mathrm{FRH} / \mathrm{BD} / 118163 / 2016)$. 


\section{CONCEPCIONES Y PRÁCTICAS DE EVALUACIÓN DE REDACCIÓN: FORMACIÓN EN SANTO TOMÉ Y PRÍNCIPE}

\section{RESUMEN}

En este artículo, se analizan las concepciones y prácticas reportadas de 19 profesores de Portugués en Santo Tomé, como punto de partida para un taller de capacitación. En un enfoque cualitativo, el análisis del contenido de datos de diferentes fuentes (cuestionario, reflexiones en el cuaderno de anotaciones diarias y registros de la investigadora) fue privilegiado. Los principales resultados revelan que la enseñanza y la evaluación de la producción escrita no están completamente ausentes de las prácticas de estos profesores, pero son ocasionales y, a menudo, no están programadas, lo que genera limitaciones. Pensando que las lagunas en la formación del profesorado cuanto a la evaluación influyen en las concepciones y prácticas, se argumenta que la formación continuada, basada en las necesidades de los profesores, contribuirá a su desarrollo profesional.

PALABRAS CLAVE EVALUACIÓN DEL APRENDIZAJE • REDACCIÓN • SANTO TOMÉ Y PRÍNCIPE • EVALUACIÓN CONTINUA.

\section{CONCEPTS AND PRACTICES OF WRITING ASSESSMENT: TRAINING WORKSHOP IN SAO TOME AND PRINCIPE}

\section{ABSTRACT}

In this article, the concepts and reported practices of 19 Portuguese Language teachers in Sao Tome and Principe are analyzed as a starting point for a training workshop. A qualitative approach favored the content analysis of data from different sources (questionnaire, reflections in the logbook and researcher records). The main results reveal that the teaching and assessment of writing are not totally absent from the practices of these teachers. However, they are occasional and often not planned, resulting in constraints. As we believe that gaps in teacher training on evaluation influence concepts and practices, we argue that ongoing training, based on teachers' needs, will contribute to their professional development. 


\section{INTRODUÇÃO}

Este estudo insere-se num projeto de doutoramento em desenvolvimento, que tem como principal objetivo compreender de que modo a formação contínua (FC) de professores potencia o seu desenvolvimento profissional sobre ensino, aprendizagem e avaliação (EAA) da escrita, concretamente por meio de uma oficina de formação (OF). Neste artigo, pretende-se apresentar e discutir resultados da investigação sobre conceções e práticas relatadas de avaliação da produção escrita dos professores que participaram na OF, reveladas no seu início, com o intuito de, posteriormente, compreenderem-se eventuais mudanças que tenham ocorrido e refletir sobre os fatores que as poderiam ter potenciado ou dificultado.

Os participantes são 19 professores são-tomenses ${ }^{2}$ que lecionavam a disciplina de Língua Portuguesa (LP) no $2^{\circ}$ ciclo do ensino básico (CEB). Sendo um trabalho de natureza qualitativa (BOGDAN; BIKLEN, 1994), seguiu-se uma abordagem metodológica de estudo de caso, em que o caso consiste no processo de construção de conhecimento profissional sobre EAA da produção escrita desse grupo de professores. Para tratamento dos dados, privilegiou-se a análise de conteúdo (BARDIN, 2011).

Nas seç̧ões seguintes, faz-se um breve enquadramento da OF desenvolvida (GORGULHO et al., 2020), cuja conceção teve em consideração o perfil geral da população de professores são-tomenses de LP do $2^{\circ} \mathrm{CEB}$, traçado num momento anterior deste estudo de doutoramento (GORGULHO et al., 2018), bem como o referencial teórico enquadrador do estudo. Apresenta-se, depois, uma caracterização genérica do grupo de participantes da OF, para seguidamente se demonstrarem e discutirem os principais resultados emergentes relativos às conceções e práticas relatadas identificadas nesses professores no início da OF. Por fim, tecem-se considerações finais sobre os resultados e sobre as implicações do estudo para a formação e investigação.

\section{BREVE ENQUADRAMENTO DA OFICINA DE FORMAÇÃO}

A OF desenvolvida teve por base o conhecimento das necessidades e interesses formativos de professores de LP do $2^{\circ}$ CEB de São Tomé e Príncipe (STP) (SÃO TOMÉ E PRÍNCIPE, 2012; COSTA et al., 2017), bem como as metas de desenvolvimento definidas pelos sucessivos ministérios da educação (ME) do país, que objetivam uma melhoria do sistema de avaliação das aprendizagens e, também, a valorização e profissionalização docente (SÃO TOMÉ E PRÍNCIPE, [s.d.]). As características de uma OF pressupõem que se desenvolvam metodologias e recursos pedagógico-didáticos 
que sejam relevantes para a sala de aula e que potenciem a melhoria da ação docente, razão pela qual foi essa a modalidade formativa implementada, já que se pretendia uma relação dialógica entre teoria e prática, isto é, entre a sala de formação e a sala de aula. No mesmo sentido, a OF ancorou-se no conhecimento científico em torno de três eixos teóricos estruturais do estudo: (i) avaliação dos alunos (ao nível de princípios gerais e conceptuais); (ii) Didática da Escrita; e (iii) desenvolvimento profissional docente.

\section{REFERENCIAL TEÓRICO ENQUADRADOR}

\section{Avaliação dos alunos}

A avaliação é parte integrante do ensino e da aprendizagem (EA), não podendo, por isso, dissociar-se desse processo. Nessa perspetiva, um dos eixos estruturais do estudo é a avaliação para a e como aprendizagem. A investigação tem evidenciado que a avaliação é uma fase fundamental do desenvolvimento curricular, sendo simultaneamente um processo e um produto, e assumindo-se como uma entidade autónoma, com princípios próprios.

De acordo com Bennett (2011), uma definição básica de avaliação em educação aponta para o desenvolvimento de quatro atividades essenciais: planear as situações para recolher evidências, recolher evidências, interpretá-las e atuar sobre as interpretações. É, portanto, um processo que consiste em estabelecer uma comparação entre o que foi alcançado e aquilo que se pretendia atingir, ou seja, entre o referido e o referente (HADJI, 1994).

De modo geral e mais frequente, o trabalho escolar organiza-se, tendencialmente, em torno de dois eixos, que se concretizam em dois tempos aparentemente distintos: um primeiro que se prende com o desenvolvimento dos conteúdos - "dar a matéria” - e que ocupa a maior parte do tempo; e um segundo destinado às tarefas de avaliação sumativa, geralmente configurado em testes no final do período (ROLDÃO; FERRO, 2015). Nesse sentido, muitas vezes a avaliação surge como um exercício isolado, dando-se destaque à ideia de educação como transmissão de conhecimentos que são classificados num teste igual para todos, que se encarregará de selecionar os alunos que estiverem aptos.

Não obstante essa realidade, estudos no campo do desenvolvimento curricular constituem um gerador relevante de articulação entre avaliação e EA, situando a avaliação como elemento integrador de regulação do processo de desenvolvimento curricular (BARREIRA, 2019). A avaliação, no sentido formativo, deve ser considerada uma atividade de regulação permanente, na qual o feedback conduza à melhoria da prática educativa. 


\section{Didática da Escrita}

Não é possível pensar em avaliação sem aludir à didática. Do mesmo modo, não faz sentido falar de didática sem se referir a avaliação. Nessa linha de pensamento, o segundo eixo teórico-estrutural relaciona-se com princípios didáticos inerentes ao EA da produção escrita. A Didática da Escrita pode ser vista como uma das subáreas da Didática do Português enquanto disciplina que procura focar dimensões específicas do uso da língua (CARVALHO, 2019).

A escrita é uma competência fundamental na vida de qualquer indivíduo, competência que é complexa e que necessita de aprendizado formal e prática o longo da escolaridade. De facto, para a produção de um texto é necessário mobilizar diferentes competências, como a competência compositiva, relativa à forma de combinar expressões linguísticas para elaborar um texto; a competência ortográfica, relativa às normas que estabelecem a representação escrita das palavras; a competência gráfica, referente à capacidade de inscrever num suporte material os sinais em que assenta a representação escrita (SOUSA, 2011). Essa complexidade caracteriza-se, também, pelo facto de ser um processo diferido, em que o destinatário não está na presença do escrevente quando descodifica o texto, pelo que, para que este possa funcionar autonomamente, o momento da produção envolve o domínio de competências que garantam a coesão e a coerência textual.

A Didática da Escrita surge, pois, como resposta às dificuldades de aprendizagem da escrita que se foram presenciando. A constatação de que "não se aprende a escrita em geral, mas em função dos textos a serem produzidos e das situações de comunicação em que são postos em funcionamento" (DOLZ; GAGNON; DECÂNDIO, 2010, p. 18) dá sentido à utilização de ferramentas pedagógico-didáticas que auxiliem o EAA da produção escrita, de que é exemplo a sequência didática (SD). Nesse contexto, as SD correspondem a conjuntos de aulas organizadas com o propósito de trabalhar a escrita de um determinado género textual, articulando naturalmente outros domínios da língua - comunicação oral, leitura, conhecimento explícito da língua (SÃO TOMÉ E PRÍNCIPE, 2010) - com situações comunicativas definidas.

A SD é um dispositivo didático que possibilita o EAA da produção escrita e que tem uma estrutura base que contempla quatro fases fundamentais: apresentação da situação; elaboração da produção inicial; desenvolvimento dos módulos de ensino, em quantidade variável; reescrita da produção inicial, em que a escrita é claramente assumida como um processo e não somente como um produto (DOLZ; GAGNON; DECÂNDIO, 2010; PEREIRA; GRAÇA, 2015). No decorrer desse processo, a avaliação adquire importância crescente pelo seu carácter regulador, que possibilita aos alunos a consciencialização das suas aprendizagens e aos professores o acompanhamento próximo desse processo, permitindo-lhes fazer as 
adaptações necessárias para atingir os objetivos estabelecidos (BARREIRA, 2019; FERNANDES, 2019).

\section{Desenvolvimento profissional docente}

A FC assume-se como espaço de excelência do (e para o) desenvolvimento profissional por ser um suporte potenciador de oportunidades de aprendizagem, sobretudo pela centralidade que a experiência docente adquire nos processos de transformação profissional, de construção de conhecimento e, inclusivamente, de mudança de práticas (GONÇALVES, 2011; VIEIRA, 2011). A importância da FC é reconhecida na Lei de Bases do Sistema Educativo de STP (Lei n. 4/2018), em que se afirma que essa formação "complementa e actualiza a formação de base numa perspectiva de educação permanente e de aprendizagem ao longo da vida" (SÃO TOMÉ E PRÍNCIPE, 2019, p. 130).

Além do mais, o próprio processo de aprender a ensinar conduz a uma construção de conhecimento profissional, com todos os saberes, de diferentes fontes e dimensões, que lhe são inerentes. O desenvolvimento profissional envolve saberes de nível "teórico (declarativo) e prático (processual), normativo e reflexivo, capaz de transformar o conhecimento existente em conhecimento relevante para ensinar e educar", sendo, por isso, atualizado em situações de prática educativa (LOURENÇO; ANDRADE; MARTINS, 2017, p. 80).

\section{DESENVOLVIMENTO DA FORMAÇÃO}

A OF foi dinamizada por duas formadoras, entre 16 de abril e 20 de maio de 2019. A formadora principal (e primeira autora deste artigo) é professora do ensino básico e doutoranda de uma universidade pública portuguesa, e a segunda formadora era, à data, supervisora pedagógica de LP para o ensino básico do ME de São Tomé e Príncipe. O envolvimento da segunda formadora foi fundamental, quer pelo conhecimento profundo do contexto em que o estudo se desenvolveu, quer pela legitimação da intervenção das formadoras junto dos professores, nomeadamente em suas salas de aula.

A OF teve como objetivos principais: (i) incrementar os conhecimentos científicos e pedagógico-didáticos de professores são-tomenses de LP do $2^{\circ} \mathrm{CEB}$, nomeadamente sobre avaliação dos alunos; (ii) desenvolver competências de avaliação dos alunos, em particular no domínio da produção escrita; e (iii) promover competências de planificação e construção de materiais pedagógico-didáticos que auxiliem o processo de EAA da escrita.

Essa OF contemplou sete sessões presenciais (num total de 28 horas) de natureza teórico-prática, em que foram apresentados e discutidos conteúdos sobre princípios gerais e conceptuais da avaliação dos alunos, sobre o EA da produção escrita 
e sobre a avaliação da produção escrita. Nas sessões exploraram-se, também, propostas de tarefas para o EAA da produção escrita no $2^{\circ} \mathrm{CEB}$ e procurou-se que os professores construíssem, em grupo, SD nesse domínio, para conteúdos programáticos de LP para o $2^{\circ} \mathrm{CEB}$. Para além de as formadoras terem monitorizado o trabalho desenvolvido pelos formandos no decorrer da OF, gerou-se uma dinâmica de partilha de experiências e de reflexão sobre o trabalho realizado.

A OF estruturou-se em três fases. Na fase 1 (sessões I a III) procurou-se contribuir para um aprofundamento de conhecimentos acerca da avaliação da produção escrita em LP, momento em que foi aplicado um questionário $(\mathrm{Q})$ de caracterização dos participantes; a fase 2 (sessões IV a VI) destinou-se à mobilização de aprendizagens e conhecimentos para o contexto profissional; e a fase 3 (sessão VII) reservou-se à apresentação dos trabalhos desenvolvidos sobre as SD e à discussão das aprendizagens realizadas. ${ }^{3} \mathrm{O}$ trabalho teórico-prático foi acompanhado de uma reflexão em diário de bordo (DB), realizada pelos professores após cada sessão presencial, com base no assunto principal da sessão, conforme se ilustra no Quadro 1. Essas reflexões foram discutidas no início da sessão seguinte, através da partilha dialogada do que cada um tinha escrito. No final da OF, foi-lhes solicitado um relatório individual.

3 As sessões presenciais realizaram-se, respetivamente, em 16 de abril, 17 de abril, 18 de abril, 22 de abril, 29 de abril, 6 de maio e 14 de maio de 2019. De 14 a 20 de maio, o trabalho autónomo dos formandos foi acompanhado, a distância, pela formadora principal. Mais detalhes sobre o plano da OF estão disponíveis em Gorgulho et al. (2020). 
QUADRO 1 - Plano geral das sessões presenciais, com referência ao tópico para reflexão, em diário de bordo e no relatório individual

\begin{tabular}{|c|c|c|c|}
\hline SESSÕES & OBJETIVOS ESPECÍFICOS & $\begin{array}{l}\text { CONTEÚDOS E } \\
\text { OPERACIONALIZAÇÃO }\end{array}$ & TÓPICO PARA REFLEXÃO \\
\hline | & $\begin{array}{l}\text { 1. Partilhar experiências de sala } \\
\text { de aula no que diz respeito à } \\
\text { avaliação; } \\
\text { 2. Aprofundar conhecimentos } \\
\text { sobre avaliação; } \\
\text { 3. Refletir em torno de princípios } \\
\text { gerais e conceptuais sobre } \\
\text { avaliação. }\end{array}$ & $\begin{array}{l}\text { - Apresentação e contextualização } \\
\text { do trabalho a desenvolver na OF e } \\
\text { da metodologia de avaliação dos } \\
\text { formandos; } \\
\text { - Resposta a um questionário de } \\
\text { caracterização dos formandos; } \\
\text { - Princípios gerais e conceptuais } \\
\text { sobre avaliação dos alunos. }\end{array}$ & $\begin{array}{l}\text { O que pensava, antes } \\
\text { desta sessão, e o que } \\
\text { penso agora, sobre } \\
\text { avaliação? } \\
\text { O que é e para que serve? }\end{array}$ \\
\hline II & $\begin{array}{l}\text { 1. Refletir em torno de questões } \\
\text { sobre o ensino da escrita; } \\
\text { 2. Aprofundar conhecimentos } \\
\text { sobre sequências didáticas (SD); } \\
\text { 3. Refletir sobre propostas de SD } \\
\text { apresentadas; } \\
\text { 4. Planificar SD para trabalho em } \\
\text { torno de géneros textuais. }\end{array}$ & $\begin{array}{l}\text { - O ensino da escrita; } \\
\text { - Sequência didática - trabalho em } \\
\text { torno dos géneros textuais; } \\
\text { - Exploração de propostas para a } \\
\text { sala de aula - trabalho em grupos; } \\
\text { - Discussão coletiva sobre as } \\
\text { propostas exploradas; } \\
\text { - Planificação do trabalho a } \\
\text { desenvolver na fase } 2 \text {. }\end{array}$ & $\begin{array}{l}\text { Relato de um episódio de } \\
\text { ensino da escrita ocorrido } \\
\text { no } 2^{\circ} \text { período, por } \\
\text { exemplo, o que planificou, } \\
\text { como correu a aula, } \\
\text { dificuldades dos alunos, } \\
\text { como avaliou. }\end{array}$ \\
\hline III & $\begin{array}{l}\text { 1. Aprofundar conhecimentos } \\
\text { sobre a avaliação da produção } \\
\text { escrita dos alunos em LP; } \\
\text { 2. Explorar o programa do 2 CEB } \\
\text { para a disciplina de LP, Domínio da } \\
\text { Escrita; } \\
\text { 3. Refletir sobre propostas } \\
\text { apresentadas; } \\
\text { 4. Planificar SD para trabalho em } \\
\text { torno de géneros textuais. }\end{array}$ & $\begin{array}{l}\text { - Avaliação da produção escrita } \\
\text { dos alunos do } 2 \text { CEB em LP; } \\
\text { - Continuação da planificação do } \\
\text { trabalho a desenvolver na fase } 2 \text {. }\end{array}$ & $\begin{array}{l}\text { Que papel assume a } \\
\text { avaliação no dia a dia } \\
\text { da minha sala de aula, } \\
\text { durante o processo de } \\
\text { ensino e aprendizagem da } \\
\text { escrita? Que avaliação é } \\
\text { que faço? }\end{array}$ \\
\hline IV & $\begin{array}{l}\text { 1. Aprofundar conhecimentos } \\
\text { sobre o processo de construção } \\
\text { de instrumentos de avaliação; } \\
\text { 2. Explorar propostas de } \\
\text { instrumentos de avaliação } \\
\text { para a disciplina de LP } \\
\text { (preferencialmente para a escrita); } \\
\text { 3. Ultimar as planificações das SD. }\end{array}$ & $\begin{array}{l}\text { - Procedimentos e instrumentos } \\
\text { de avaliação; } \\
\text { - Monitorização do trabalho em } \\
\text { desenvolvimento (SD). }\end{array}$ & $\begin{array}{l}\text { Que instrumentos de } \\
\text { avaliação (da escrita) } \\
\text { costumo usar? Que uso } \\
\text { faço das informações } \\
\text { que registo nesses } \\
\text { instrumentos? De } \\
\text { que modo são úteis? } \\
\text { (exemplos concretos) }\end{array}$ \\
\hline V & $\begin{array}{l}\text { 1. Definir critérios de avaliação, } \\
\text { tendo em conta os objetivos de } \\
\text { aprendizagem; } \\
\text { 2. Definir indicadores para os } \\
\text { critérios estabelecidos; } \\
\text { 3. Refletir sobre propostas } \\
\text { apresentadas. }\end{array}$ & $\begin{array}{l}\text { - Definição de critérios de } \\
\text { avaliação; } \\
\text { - Monitorização do trabalho em } \\
\text { desenvolvimento (SD). }\end{array}$ & $\begin{array}{l}\text { A forma como os } \\
\text { critérios de avaliação são } \\
\text { construídos influencia o } \\
\text { processo de avaliação? } \\
\text { Por quê? }\end{array}$ \\
\hline VI & $\begin{array}{l}\text { 1. Discutir a articulação entre } \\
\text { avaliação formativa e avaliação } \\
\text { sumativa; } \\
\text { 2. Refletir sobre propostas } \\
\text { apresentadas. }\end{array}$ & $\begin{array}{l}\text { - Avaliação formativa e sumativa: } \\
\text { integradas no processo de ensino } \\
\text { e aprendizagem; } \\
\text { - Monitorização do trabalho em } \\
\text { desenvolvimento (SD). }\end{array}$ & $\begin{array}{l}\text { Tenho preparado os meus } \\
\text { alunos para produzirem } \\
\text { textos? Como? } \\
\text { Se não, o que me } \\
\text { "falta" fazer/modificar } \\
\text { nas minhas práticas/ } \\
\text { estratégias de ensino e de } \\
\text { avaliação? }\end{array}$ \\
\hline VII & $\begin{array}{l}\text { 1. Partilhar o resultado do trabalho } \\
\text { de grupo desenvolvido ao longo } \\
\text { do período de formação; } \\
\text { 2. Refletir sobre a mobilização das } \\
\text { propostas apresentadas para a } \\
\text { sala de aula; } \\
\text { 3. Avaliar a OF, fazendo um } \\
\text { balanço global. }\end{array}$ & $\begin{array}{l}\text { - Apresentação oral dos trabalhos } \\
\text { desenvolvidos pelos professores- } \\
\text {-formandos, no decorrer da OF; } \\
\text { - Reflexão sobre as propostas } \\
\text { pedagógico-didáticas } \\
\text { desenvolvidas e sua mobilização } \\
\text { em sala de aula; } \\
\text { - Avaliação global da OF. }\end{array}$ & $\begin{array}{l}\text { Relatório final individual, } \\
\text { descritivo e reflexivo } \\
\text { sobre o trabalho } \\
\text { desenvolvido ao longo } \\
\text { da OF. }\end{array}$ \\
\hline
\end{tabular}

Fonte: Elaboração das autoras com dados do estudo. 
De notar que houve um acompanhamento in loco pelas formadoras, mediante a observação de uma ou duas aulas de cada professor. Após cada semana de observação, as formadoras deram feedback global na sessão presencial seguinte, de modo a discutirem-se aspetos considerados mais relevantes para o grupo. Além desse feedback global, após a observação de cada aula solicitou-se que cada professor fizesse uma autoavaliação reflexiva, por escrito, e procurou-se dar um retorno individualizado. No final da OF, os formandos apresentaram o trabalho de grupo desenvolvido e entregaram um relatório individual, descritivo e reflexivo, em que foi feito um balanço do seu percurso na OF. Na Figura 1 ilustra-se como ocorreu a articulação sala de aula vs. sala de formação ao longo da OF.

FIGURA 1 - Organização geral da articulação entre a sala de formação e a sala de aula, durante a OF

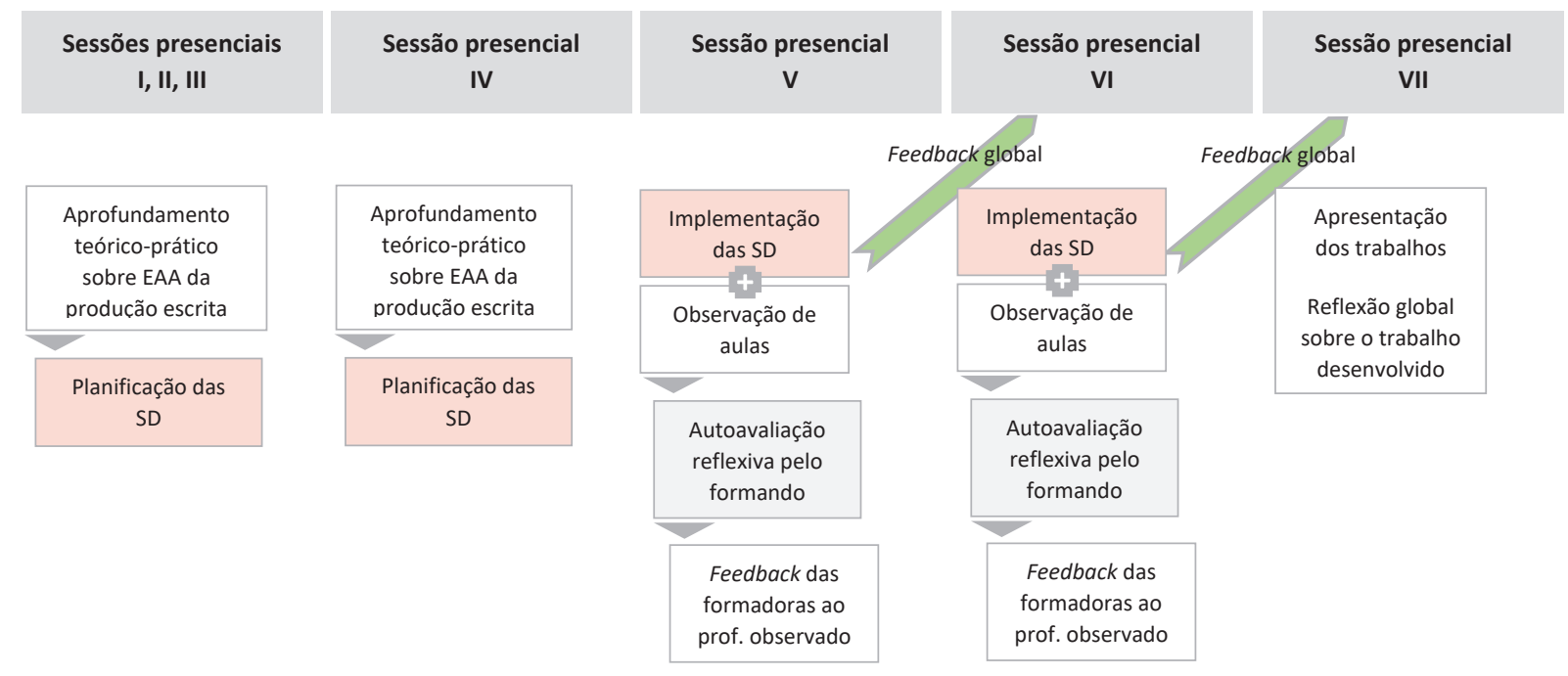

Fonte: Elaboração das autoras com dados do estudo.

\section{CARACTERIZAÇÃO DOS FORMANDOS}

Para a caracterização dos formandos que participaram na OF, recorreu-se a um questionário ${ }^{4}$ que foi respondido pelos professores no início da formação. O grupo era constituído por seis professores do sexo masculino e 13 do sexo feminino, com idades compreendidas entre os 25 e os 61 anos, sendo a mediana os 32 anos e o desvio padrão de 8,8 anos. No Gráfico 1 apresenta-se a caracterização desses professores no que respeita ao seu nível de formação. No Gráfico 2, observa-se a

4 Estruturado em quatro secções - habilitações literárias, atuação enquanto delegado de disciplina, práticas de avaliação da produção escrita dos alunos e realização de formação sobre avaliação da produção escrita. Com ligeiras alterações no questionário referido em Gorgulho et al. (2018). 
percentagem de professores que detinha o grau de licenciatura, quer na área de LP, quer noutras, que se referem adiante.

GRÁFICO 1 - Nível de formação dos participantes da OF

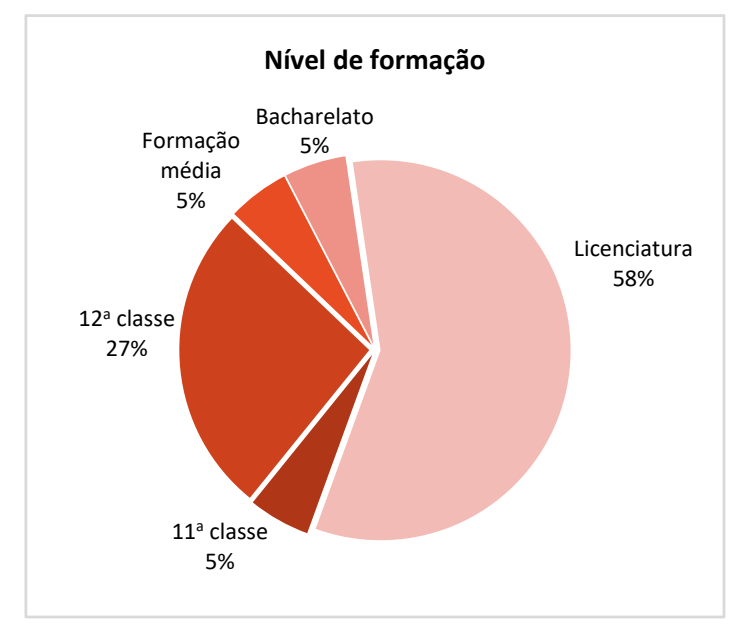

Fonte: Elaboração das autoras com dados do estudo.

GRÁFICO 2 - Área de formação dos detentores de diploma do grau de licenciatura

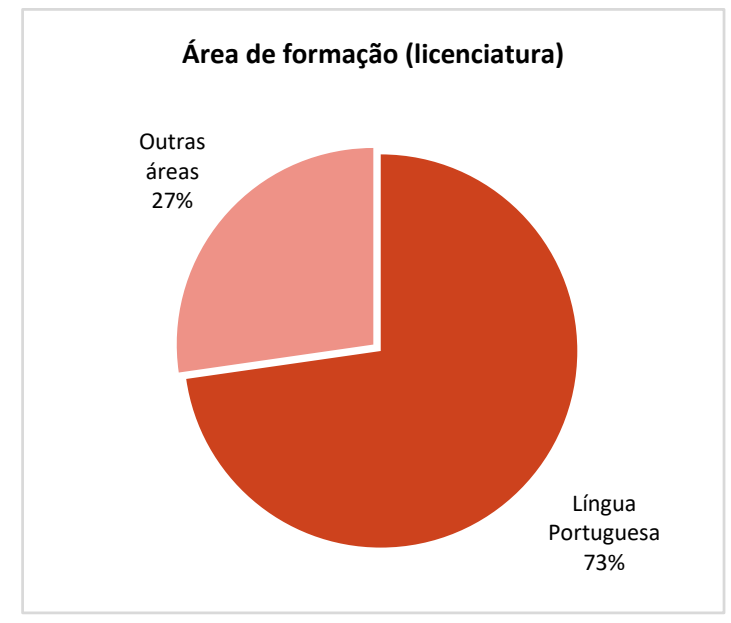

Fonte: Elaboração das autoras com dados do estudo.

Verifica-se que a maioria dos professores $(\mathrm{N}=11)$ tinha o grau de licenciatura, embora nem todos tenham realizado essa formação na área em que lecionam. Com efeito, apenas oito do total de professores licenciados fez a licenciatura em LP (Gráfico 2). Os outros três professores concluíram as suas licenciaturas em Direito, Relações Públicas e Geografia. Registou-se, ainda, que um dos professores tinha 
bacharelato em História, um tinha concluído formação média ${ }^{5}$ e seis tinham apenas o ensino secundário. Embora não seja pretendido, nem possível, fazer generalizações estatísticas para todos os professores são-tomenses que lecionam LP no $2^{\circ} \mathrm{CEB}$, esses resultados poderão constituir um indicador de que a situação da não habilitação docente em STP está a mudar, uma vez que, de entre os professores que não tinham formação específica para lecionar LP (11 em 19), à data da realização da OF, sete estavam a frequentar licenciaturas nessa área.

Uma das perguntas do $Q$ destinou-se a conhecer qual formação os formandos teriam realizado, anteriormente, sobre avaliação da escrita dos alunos. Registou-se que dez professores afirmaram ter feito formação sobre essa temática no âmbito de disciplinas da sua formação inicial (Metodologia de Ensino da Língua Portuguesa, Introdução às Ciências de Educação, Técnica de Expressão Oral e Escrita e Organização do Desenvolvimento Curricular), cinco professores referiram ações de FC, promovidas no âmbito do projeto Escola+, tendo apresentado as designações "Formação modular em Língua Portuguesa" e "Oficina de Escrita". Destacam-se, ainda, cinco professores que afirmaram não ter feito qualquer formação nesse âmbito.

\section{SISTEMATIZAÇÃO E DISCUSSÃO DOS PRINCIPAIS RESULTADOS EMERGENTES}

Para se conhecerem as conceções e práticas relatadas desse grupo de professores, procedeu-se, primeiramente, à sistematização, por participante, dos dados provenientes: (i) das respostas ao $Q$ de caracterização do perfil dos participantes da OF; (ii) das reflexões em DB dos professores, relativas às sessões I a IV, já que se considerou que a partir da sessão $\mathrm{V}$ as conceções e práticas inicialmente identificadas estariam a mudar; e (iii) das notas de campo da investigadora (NC), relativamente às primeiras quatro sessões presenciais. Para este texto, focam-se os aspetos considerados mais relevantes para compreensão das conceções e práticas relatadas desses professores, destacando-se e discutindo-se os principais resultados emergentes, com base na triangulação efetuada.

A triangulação de resultados semelhantes provenientes do corpus em análise permitiu operacionalizar a categorização. Esse processo incluiu a definição de categorias, subcategorias e indicadores de análise, que pretendem dar sentido às subcategorias e contribuir para garantir a validade interna da análise. A contabilização dos elementos do corpus ocorreu por professor e não por ocorrência. De

5 Contempla "3 anos de formação profissional, iniciada a partir da 9a classe, que em alguns casos conferiu certificado de conclusão do ensino secundário". Disponível em: Escola+, Fase II (2017). Caracterização do Corpo Docente do Ensino Secundário de São Tomé e Príncipe, 2016/17. Anexo ao Relatório Final de Execução do Projeto. Lx/STP: Instituto Marquês de Valle Flôr, 2017. p. 3. 
notar que se verificou que existem diferentes tendências nos resultados encontrados, isto é, professores com conceções e práticas relatadas diferenciadas. Em alguns casos, não se pode falar apenas de uma tendência num mesmo professor, no sentido de ter sido possível identificar uma associação com um único modo de pensar e fazer a avaliação da produção escrita antes da OF, na medida em que parecem existir aspetos incoerentes entre si, que apontam para conceções opostas. No entanto a intenção foi chegar a resultados com base na análise do grupo de professores e não de cada professor individualmente.

As categorias emergentes são as seguintes: (i) conceções sobre o objeto de avaliação; (ii) entendimentos da relação entre EA e avaliação da produção escrita; (iii) conceções sobre as funções da avaliação da escrita; e (iv) conceções e práticas relatadas sobre instrumentos e critérios de avaliação da produção escrita. No Quadro 2 sistematizam-se, por categoria, os principais resultados, com indicação da sua representatividade $(\mathrm{N})$ dentro do grupo. A discussão desses resultados, que se segue, realiza-se em função da categorização concretizada. ${ }^{6}$

QUADRO 2 - Sistematização, por categoria e subcategoria, dos principais resultados emergentes, relativos a conceções e práticas iniciais relatadas

\begin{tabular}{|l|l|}
\hline CATEGORIAS & SUBCATEGORIAS \\
\hline $\begin{array}{l}\text { 1. Conceções sobre o objeto } \\
\text { de avaliação (produção } \\
\text { escrita) }\end{array}$ & $\begin{array}{l}\text { - Conceções inadequadas sobre o que é produzir textos escritos }(\mathrm{N}=6) \\
\text { - Desvalorização da produção escrita }(\mathrm{N}=19)\end{array}$ \\
\hline $\begin{array}{l}\text { 2. Entendimentos da } \\
\text { relação entre EA e } \\
\text { avaliação da produção } \\
\text { escrita }\end{array}$ & $\begin{array}{l}\text { - Práticas relatadas de EA da escrita desfasadas da sua avaliação }(\mathrm{N}=19) \\
\text { - Ausência de feedback aos alunos no processo de avaliação da escrita }(\mathrm{N}=17)\end{array}$ \\
\hline $\begin{array}{l}\text { 3. Conceções sobre as } \\
\text { funções da avaliação da } \\
\text { escrita }\end{array}$ & $\begin{array}{l}\text { - Função reguladora }(\mathrm{N}=9) \\
\text { - Função classificatória }(\mathrm{N}=12)\end{array}$ \\
\hline $\begin{array}{l}\text { 4. Conceções e práticas } \\
\text { relatadas sobre } \\
\text { instrumentos e critérios } \\
\text { de avaliação da produção } \\
\text { escrita }\end{array}$ & $\begin{array}{l}\text { - Conceções aproximadas do que é um instrumento de avaliação }(\mathrm{N}=9) \\
\text { - Conceções erróneas do que é um instrumento de avaliação ( } \mathrm{N}=5) \\
\text { - Dificuldade de construção e utilização de instrumentos de avaliação da escrita } \\
\text { - Dificuldade de construção de critérios para a avaliação da escrita }(\mathrm{N}=8)\end{array}$ \\
\hline
\end{tabular}

Fonte: Elaboração das autoras com dados do estudo.

\section{Conceções sobre o objeto de avaliação}

Destacam-se algumas conceções sobre o que é produzir textos que se podem considerar inadequadas, por referência ao defendido na literatura, que foram possíveis de

6 Ao longo do texto são referidos alguns exemplos, nomeadamente de reflexões em $D B$, sendo utilizado o código Px_DB_y, em que Px identifica o participante (x varia de 1 a 19) e DB_y identifica a reflexão do DB, correspondente ao tópico das sessões presenciais (y varia de I a IV). 
identificar em cerca de um terço do grupo (6 em 19), quer em respostas ao $Q$, quer nas reflexões em DB, como também nas sessões presenciais (NC). As conceções que se elencam estão algo desfasadas dos pressupostos atuais da Didática da Escrita (CARVALHO, 2019; PEREIRA; GRAÇA, 2015).

Escrever um texto é reproduzir outros textos, por exemplo, um texto que foi escrito no quadro e que os alunos copiam para os seus cadernos. Não negando que exercícios de reprodução sejam necessários para praticar determinados aspetos da escrita, como a ortografia, por exemplo, parece ser inquestionável que reproduzir um texto não é o mesmo que produzi-lo. É necessário que existam momentos de produção escrita como modo de apropriação e de construção do saber (CARDOSO, 2009).

Produzir textos é formar um conjunto de palavras ou um conjunto de frases. Sendo a produção escrita um exercício de reconhecida complexidade, não pode ser reduzido à aglutinação de palavras, ou mesmo de frases, sem referência a aspetos como coesão e coerência entre essas frases, ou seja, sem referência ao conceito de "texto”. Além do mais, são características sem as quais um texto escrito dificilmente se torna compreensível pelo recetor e, portanto, não serve o propósito da sua realização - o de ser ler lido por um recetor, após a sua produção, pelo emissor, num momento diferente ao da sua produção (CARVALHO, 2019).

Produzir textos é um meio para outro fim, por exemplo, para responder por escrito a perguntas de interpretação de um texto lido, em que a avaliação (dessa escrita) passa pela verificação do conhecimento demonstrado, em relação ao texto estudado. É evidente que é preciso (saber) escrever para responder, por escrito, a perguntas, e que, de algum modo, ao responder a essas perguntas também se está a praticar a competência de escrita. Contudo o que ressalta deste estudo é que a noção de produção textual parece remeter para a escrita como um meio e não como um objetivo em si mesmo, quando a literatura evidencia que é preciso ensinar explicitamente a escrever determinados géneros textuais (CARVALHO, 2019; PEREIRA; GRAÇA, 2015).

Percecionámos uma desvalorização generalizada do ensino da produção escrita, o que permite, também, uma compreensão dos entendimentos que esses professores têm sobre o objeto de avaliação em causa e sobre o lugar e a importância que lhe atribuem, nas suas práticas.

A ausência de intencionalidade pedagógica é percetível pela escassa referência (de apenas quatro professores), nas reflexões em DB, à planificação de aulas de produção escrita, de que se infere que os exercícios ou atividades de produção escrita surgem como consequência de outros objetivos. A formadora local, com vasta experiência de supervisão de aulas de LP, confirmou, numa das sessões presenciais, a ausência de hábitos de planificação de aulas de escrita. Das NC da investigadora 
também ressalta essa dificuldade em planificar o EAA da escrita, como resposta ao trabalho que foi proposto desenvolver no âmbito da OF, que se entende poder estar relacionada com o facto de não ser uma prática comum, uma vez que não se verificou a mesma dificuldade para a leitura e a interpretação textual, por exemplo, que naturalmente foram pensadas em articulação com o ensino da escrita.

As atividades de produção escrita são deixadas para o final da aula, sem se fazer referência, na maioria das vezes, a nenhuma orientação dada aos alunos para além da indicação do tema do texto a escrever que, por norma, está relacionado com o assunto do texto lido previamente. Esse hábito de deixar a produção escrita para o fim parece não lhe atribuir lugar de destaque na aula, o que foi notório em relatos de aulas nos DB e também confirmado nas discussões que se geraram nas sessões presenciais (NC).

A ausência de planificação e estruturação dos textos, nas práticas relatadas, conduz à perceção de que parece não existir hábito de uma organização prévia das ideias e informações a escrever pelas várias partes que compõem o texto. O exercício de fazer a "chuva de ideias" foi o mais referido pelos professores (5 em 19, nos DB) e corresponde a um levantamento de ideias do tema sobre o qual se vai escrever, assumindo uma grande importância, pois efetivamente "ninguém pode escrever sobre um tema de que não sabe nada ou em que nunca pensou” (LUCIANO; SÁ, 2019, p. 11). Não obstante há outros aspetos a considerar na planificação, nomeadamente predefinir o que escrever em cada parte do texto e a ordem pela qual as ideias são apresentadas, prática que não parece ser habitual nesse grupo de professores.

A sobrevalorização da escrita de textos escolares, como narrativas e poemas, por uma maioria de professores (11 em 19), no Q e nos DB, parece estar de acordo com o que estudos nesse campo têm demonstrado, de que se assiste a uma maior incidência de textos narrativos, em detrimento de outros tipos de textos. Essas práticas de escrita são maioritariamente artificiais, sem consideração das diferentes intenções discursivas, cujos produtos não têm outro propósito se não serem corrigidos (quando o são) pelo professor (CARVALHO, 2019). Além disso emerge um entendimento que parece ser pouco centrado num ensino que atenda ao contexto e às individualidades dos alunos, mas que antes parece procurar "receitas", evidenciado em perguntas que os professores iam fazendo ao longo das sessões, de que é exemplificativa a seguinte: "Quantas aulas são precisas para aprender a escrever, em média?" (NC_SP_iv).

Vejamos os exemplos do Quadro 3, que são ilustrativos das situações acima descritas. 
QUADRO 3 - Exemplos ilustrativos que evidenciam conceções sobre a produção escrita e o seu ensino

\footnotetext{
"No segundo período, planificamos a produção escrita de um pequeno texto sobre as tartarugas marinha como actividade de pré-leitura do texto As ilhas das tartarugas. [...] Em primeiro lugar fizemos uma chuva de ideia, ou seja, do conhecimento que os alunos já têm sobre as tartaruga. Foi um trabalho muito rico. [...] Alguns trouxeram livro sobre as tartarugas. Aproveitei para ler o livro e enrequecer o conhecimento dos outros alunos. E a partir a historia do livro eles produziram belos textos. [...] A maior dificuldade e que não tive tempo suficiente para corrigir todos os caderno e dar retorno aos meus alunos. [...] O tempo também não foi suficiente para fazermos a revisão o trabalho de melhorar o texto. [...] Quanto a avaliação fiz avaliação formativa: a correcção do trabalho na sala de aula. [...] Essa actividade permitiu-me replanificar as actividade para superar algumas dificuldades encontradas bem como a reestruturar parámetros." (P3_DB_ii)

"Fiz uma aula de produção escrita sobre o texto O roubo do anel e avaliei os cadernos dos alunos no geral e especifiquei as palavras que houveram muitos erros." (P10_Q)
}

Fonte: Corpus de análise do estudo.

Legenda: P3_DB_ii = Reflexão em diário de bordo, relativa à sessão II, do formando P3; P10_Q = Resposta a um item do questionário pelo formando P10.

\section{Entendimentos da relação entre EA e avaliação da escrita}

Emergiram conceções iniciais, generalizadas nesse grupo de professores, segundo as quais o EAA parece não ser visto como um processo uno, mas que aponta antes para uma separação dos momentos de ensinar e aprender dos momentos de avaliar.

Parece haver inconsistência entre a valorização, ao nível do discurso escrito (DB), da dimensão da avaliação contínua da escrita, em contraste com a ausência de referência à avaliação nos relatos de aulas de produção escrita, o que demonstra, desde logo, esse desfasamento. Se na primeira sessão presencial transpareceram conceções que pareciam apontar para a compreensão da necessidade de planificar a avaliação juntamente com a planificação do EA, no âmbito das práticas a situação é diferente, já que se comprovou, nas sessões seguintes, a dificuldade que os professores tiveram em planificar a avaliação da escrita, no seio das SD.

Essa contradição parece estar de acordo com a mesma dificuldade que se verificou aquando da análise de respostas do Q e das reflexões em DB, em que os professores afirmaram adotar determinadas práticas de avaliação, mas tiveram dificuldade em explicitá-las, por escrito, quando solicitado. A ausência de práticas relatadas de avaliação contínua da escrita aparece também relacionada com diferentes entendimentos do que é fazer avaliação contínua. Se, por um lado, se registaram referências a uma noção de avaliação contínua que aponta para um apoio continuado durante o EA, pelo que inferimos que terá sentido formativo e que, portanto, corresponderá à noção de avaliação contínua que se defende na literatura (por exemplo BARREIRA, 2019), por outro, há referências que remetem para práticas de verificação contínua, isto é, verificação da realização (e não do seu conteúdo) de trabalhos na sala de aula, de trabalhos de casa e de outras atividades que, talvez por se realizarem de modo contínuo ao longo do ano, são confundidas com práticas de avaliação contínua. 
Transpareceu a ideia de que os professores não trabalhavam efetivamente a produção escrita e, consequentemente, não a avaliavam sistematicamente, porque consideravam que os alunos não tinham competências - designadas muitas vezes como "pré-requisitos" - que lhes permitissem aprender a fazer algo mais complexo do que escrever frases, como é o caso de escrever um texto. Vários professores afirmaram, inclusivamente, algo como "Alguns, na $5^{\mathrm{a}} / 6^{\mathrm{a}}$ classe, não conseguem sequer escrever uma frase, quanto mais um texto [...]” (NC_SP_ii). Essas considerações indiciam, porém, que de alguma forma fizeram uma avaliação da escrita dos alunos, ainda que informal.

A ausência de práticas relatadas de revisão e reescrita dos textos, com os alunos, verificada nos DB e confirmada nas sessões presenciais, remete para uma noção de produto acabado e evidencia o desfasamento entre o EA da produção escrita e a sua avaliação, já que essa prática é determinante para ser possível rever e reescrever um texto, melhorando-o. Essa noção que transparece não está de acordo com uma Didática da Escrita, segundo a qual se reforça que o texto não é um produto acabado à primeira tentativa e que é preciso voltar ao que foi escrito, avaliá-lo e melhorá-lo (BRANDÃO, 2007). O indicador anteriormente referido, de ausência de práticas relatadas de planificação e estruturação dos textos, permitia antever, como consequência, a não existência de práticas constantes de revisão e reescrita. Na verdade, se houvesse práticas de planificação do texto, a revisão, por referência àquilo que se planificou num momento inicial, faria certamente mais sentido.

Percecionámos, sobretudo nas reflexões em DB, uma ausência de feedback aos alunos, por parte da maioria dos professores (17 em 19), no processo de avaliação da escrita, que contribuiu para perceber o lugar que esses professores atribuíam à avaliação no processo de EA da produção escrita. Com efeito, apenas nas reflexões de dois professores se identificou a referência explícita à importância de dar retorno, sobretudo aos alunos com mais dificuldades, e à sua utilização como prática regular.

O desconhecimento da necessidade de dar feedback aos alunos é uma das razões que parece justificar a ausência dessa prática. Na verdade, também a literatura informa que as observações dos professores, tendencialmente, recaem sobre a primeira (e única) versão do texto, não havendo lugar para esse retorno durante o EA, nem oportunidade para revisão, avaliação e reescrita (SUASSUNA, 2012).

A dificuldade assumida de dar retorno aos alunos, inerente ao número de alunos por turma e consequente "falta de tempo" para o fazer, sobretudo de forma individual, é consistente com a manifestação, logo no $Q$, de que o número de alunos da turma influencia o processo de avaliação. Esse resultado conduz à reflexão de que, embora os professores possam reconhecer a função reguladora da avaliação, apresentam dificuldades em operacionalizá-la. 
Adicionalmente, através de práticas relatadas (embora pouco frequentes) do feedback que é dado aos alunos, transparece que as informações disponibilizadas podem não ser verdadeiramente úteis. Comentários como "fuga ao tema" ou "muitas palavras repetidas", por serem vagos, não constituem informações úteis para os alunos reescreverem e melhorarem os seus textos. Essa situação poderá estar relacionada, ainda, com o tipo de registo de avaliação dita formativa que os professores fazem, em que a utilização dos sinais + (mais) ou - (menos) não serve o propósito de conduzir os alunos à compreensão do que precisam de melhorar nos seus textos (BRANDÃO, 2007), ainda que seja uma indicação "superior" (PORTUGAL, 2016).

QUADRO 4 - Exemplos ilustrativos que evidenciam conceções sobre o EA da produção escrita e a sua avaliação

"Durante o processo e aprendizagem da escrita a avaliação assumia um papel secundário, na medida que o
fazia de forma desapaixonada, prendia muito com critérios avaliativos como a lógica, coerência, entre outros
aspectos. Não dava a devida importância porque ficava em dúvida de como avaliar as produção escrita tendo
uma turma de 49 alunos. Não sabia que era necessário dar retorno aos meus alunos de forma individual."
(P3_DB_iii)
"Depois da interpretação oral e escrita de um texto, peço que os alunos façam um resumo do texto que
acabaram de ler, produzir uma redacção, concluir uma história se for uma narrativa aberta." (P6_Q)

Fonte: Corpus de análise do estudo.

Legenda: P3_DB_iii = Reflexão em diário de bordo, relativa à sessão III, do formando P3; P6_Q = Resposta a um item do questionário pelo formando P6.

\section{Conceções sobre as funções da avaliação da escrita}

Quase metade dos professores (9 em 19) evidenciou reconhecer a função reguladora da avaliação, pelo menos no âmbito do discurso escrito, em relatos no $Q$ e em reflexões nos DB, associando-a à modalidade formativa da avaliação. Essa conceção inicial, ilustrada no Quadro 5, assume grande importância na medida em que se aproxima das conceções de avaliação defendidas na literatura de especialidade.

Essa função reguladora da avaliação foi reconhecida por quatro professores como tendo efeitos no decorrer da aula, através da recolha de evidências para a atuação no momento, situação que é referida por Hadji (1994, p. 188) ao definir regulação como a "operação de condução de uma acção que se apoia em informações de retorno (feedback) para ajustar a acção realizada ao fim perseguido".

A mesma função reguladora reconheceu-se na planificação das aulas e das opções pedagógico-didáticas do professor, de acordo com a informação que essa avaliação lhe dá e que lhe permite ajustar ou replanificar a sua ação, mediante uma reflexão sobre a informação obtida. Nesse caso, está-se perante uma regulação retroativa (HADJI, 1994), que pode conduzir, por exemplo, à planificação de atividades de remediação que permitam reincidir nos objetivos que não foram atingidos. 
Contudo esse reconhecimento, ao nível do discurso escrito, parece ser incoerente com o anterior resultado de ausência de feedback aos alunos no processo de avaliação e também com o que aponta para a dificuldade de construção e utilização de critérios de avaliação, que se verá adiante, pois uma avaliação formativa, informativa e reguladora tem de se regular necessária e primeiramente por um referente e, a partir daí, recolher um conjunto de dados que possam ser interpretados relativamente a esse referente (HADJI, 2001).

\section{QUADRO 5 - Exemplos ilustrativos que evidenciam o reconhecimento da função reguladora da avaliação}

\footnotetext{
"O papel da avaliação no dia-a-dia é ajudar o docente e avaliar a si mesmo e também a aprendizagem do aluno; a avaliação facilita o Processo de escrita; a avaliação ajuda o Professor a melhorar na aprendizagem dos alunos na Produção escrita dos textos." (P14_DB_iii)

"Antes desta sessão eu pensava que a avaliação tinha o seu peso e que ajudava o professor a analisar e a fazer uma reflexão sobre as suas práticas pedagógicas [...]." (P15_DB_i)

Fonte: Corpus de análise do estudo.

Legenda: P14_DB_iii = Reflexão em diário de bordo, relativa à sessão III, do formando P14; P15_DB_i = Reflexão em diário de bordo, relativa à sessão I, do formando P15.
}

Por contraste, então, com o reconhecimento da função reguladora, prevalece uma noção classificatória e sumativa da avaliação. Mais de metade dos professores (12 em 19) apresentou evidências, no Q, em diferentes reflexões no DB e também confirmadas pelas NC, que permitem perceber o reconhecimento de que a avaliação sumativa era aquela que privilegiavam.

Essa conceção revelou-se na descrição dos professores de que a avaliação age na "medição" e verificação do nível de aprendizagens e conhecimentos, que está de acordo com o defendido em Hadji (2001), de que a conceção de que a avaliação corresponde a uma medida do desempenho dos alunos está enraizada no entendimento dos professores.

Identificou-se a noção de que avaliar serve para atribuição de um resultado, o que de alguma forma está relacionado com a ideia de que avaliar é medir, pois essa medida corresponderá à atribuição de um número (HADJI, 1994). Esse resultado, por referência à discussão apresentada anteriormente, não surpreende. Com efeito, a avaliação de um determinado objeto relaciona-se intimamente com as conceções que o professor tem do EA do objeto dessa avaliação. Se a conceção de produção textual corresponde ao que se tem vindo a referir nesta discussão sobre os resultados emergentes, sobretudo à noção de texto como um produto acabado, não se conhecendo a importância da revisão e da reescrita, então é natural que se verifique uma prevalência de noção classificatória ou sumativa da avaliação da produção escrita, em que o que importa é revelar se o aluno "merece" ou não ser "aprovado" e qual a classificação que lhe deve ser atribuída. Os exemplos do Quadro 6 são ilustrativos dessas noções. 
QUADRO 6 - Exemplos ilustrativos que evidenciam a conceção de uma função sobretudo sumativa da avaliação

"Antes desta sessão eu pensava que a avaliação só servia para medir o grau de aprendizagem do aluno ou
seja, era visto como algo que se avalia no final e era para cumprir a burocracia." (P7_DB_i).
"No dia-a-dia na minha sala de aula, durante o processo de ensino aprendizagem da escrita a avaliação tem
o papel de controlar a turma ou seja de saber quem tem mais aptidão na área de escrita. E quem tem mais
dificuldade na mesma área para depois ajuda-los a superar. Que seja trabalhar bem esses mesmos alunos. [...]
Dou essa avaliação importância porque é essa avaliação que vai me ajudar a trabalhar na sala de aula e vai-
-me por a perceber se o aluno está á compreender a matéria dada. [...] Na minha sala de aula faço avaliação
formativa porque, depois de eu dar uma determinada matéria faço algumas perguntas orais para saber se o
alunos estavam atentos na aula ministrados por mim.” (P18_DB_iii)

Fonte: Corpus de análise do estudo.

Legenda: P7_DB_i = Reflexão em diário de bordo, relativa à sessão I, do formando P7; P18_DB_iii = Reflexão em diário de bordo, relativa à sessão III, do formando P18.

\section{Conceções e práticas relatadas sobre instrumentos e critérios para avaliação da escrita}

Destacam-se conceções sobre o que são instrumentos de avaliação, em quase metade do grupo (9 em 19), que se aproximam do que é aceite na literatura de especialidade.

Surge a referência a ferramentas de apoio para fazer a avaliação, de que são exemplo as listas de verificação e as grelhas de correção, o que está de acordo com o defendido na literatura, se considerarmos, como Hadji (1994, p. 161), por exemplo, que “o instrumento é um utensílio que facilita uma práxis, que permite apreender as coisas [...] ou agir sobre elas”. Nesse caso, os exemplos referidos pelos professores correspondem a instrumentos de observação direta, já que possibilitam "levantar informações sobre a actividade do aprendente" (HADJI, 1994, p. 165).

Referiram-se também materiais ou instrumentos para registo de informações recolhidas, surgindo o exemplo do caderno do professor, que se entende ser o local em que os professores anotam as informações que recolhem no decorrer das aulas. A afirmação, por parte de quatro professores, de que utilizavam o "caderno do professor" como instrumento de avaliação da produção escrita dos alunos poderá estar relacionada com as diretrizes da Direcção do Ensino Básico (DEB) (PORTUGAL, 2016, p. 2), de que "o registo [da avaliação formativa] deve ser feito no caderno do professor e apresentado sempre que for solicitado".

A respeito dos registos que os professores fazem nos seus cadernos, verifica-se, nesse documento da DEB (PORTUGAL, 2016, p. 2), que embora se afirme que a avaliação formativa se destina "a informar os professores sobre a qualidade do processo educativo e da aprendizagem”, consta a informação de que essa avaliação formativa deve ser registada "qualitativamente, mediante a utilização dos sinais + (mais) ou - (menos)” (PORTUGAL, 2016, p. 3). Infere-se, daqui, que se considera esse tipo de "avaliação" como qualitativa (e formativa) pelo facto de não utilizar números. No entanto o registo que se sugere fazer não traz informações úteis para o apoio ao EA, quer para o aluno, que fica sem perceber o que aquele "menos" pode 
significar, quer para o professor, pois não é informação detalhada, e a sua leitura, num momento futuro, pode não permitir o entendimento do que, à altura do registo, se pretendeu registar com essa sinalética.

Surgiram também conceções erróneas do que é um instrumento de avaliação, por contraste com o identificado anteriormente.

Conceções de instrumentos de avaliação apontam para produtos de aprendizagem sobre os quais incide a avaliação (de quatro professores), de que são exemplos resumos, exercícios, provas, trabalhos de grupo. Esses produtos são exercícios apresentados aos alunos, que vão "desencadear um comportamento, que será objecto de observação e de análise” (HADJI, 1994, p. 161). Sendo certo que a avaliação corresponde ao processo de "observação-análise-interpretação" (HADJI, 1994, p. 161) desse comportamento do aluno, do seu desempenho naquele exercício, tais produtos não correspondem a um instrumento de ou para avaliação, mas poderão conduzir, isso sim, à utilização de instrumentos que auxiliem a sua análise.

Registou-se ainda a referência a materiais de apoio ao processo de EAA, por um professor, como se de instrumentos de avaliação se tratassem, como é o caso de dicionários e gramáticas.

Foi percetível, em quase todos os professores (18 em 19), a dificuldade de construir e utilizar instrumentos que auxiliem a avaliação da produção escrita, identificada tanto nas reflexões em DB como nas sessões presenciais, durante o trabalho de construção das SD.

Por um lado, a ausência de práticas relatadas de utilização desses instrumentos deixa transparecer que, na prática, não serão utilizados instrumentos que auxiliem essa avaliação, pois, com efeito, é difícil relatar aquilo que não se faz. Os relatos vagos que dizem respeito a esse assunto não explicitam que instrumentos são utilizados, nem como e com que intenção são construídos ou adaptados pelos professores. Verificou-se que somente três professores fizeram referência a instrumentos que poderiam auxiliar a avaliação da produção escrita (listas de verificação e grelhas de correção), mas, ainda assim, com dificuldade na explicação da sua utilidade.

Por outro lado, a ausência de exemplos concretos de instrumentos utilizados, nos casos em que os professores afirmaram utilizá-los, conduz à reflexão de que tal ausência pode estar associada à dificuldade da sua construção. De notar que apenas uma professora exemplificou um dos instrumentos que afirmou utilizar, desenhando o que se assemelha a uma lista de verificação de determinados aspetos nos textos dos alunos, conforme se ilustra no Quadro 7. 
QUADRO 7 - Exemplos ilustrativos relativos a conceções e práticas relatadas sobre construção de instrumentos de avaliação

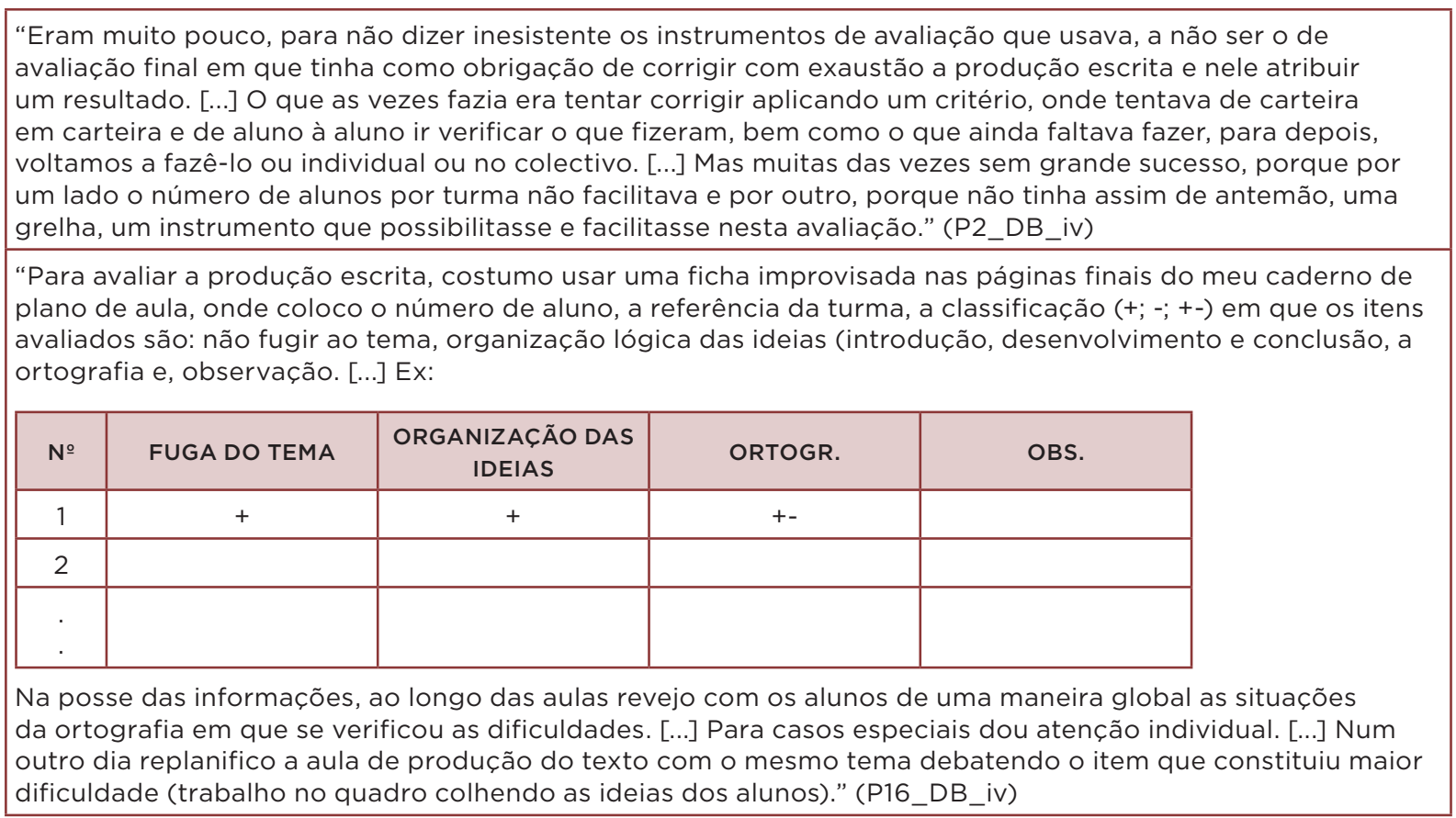

Fonte: Corpus de análise do estudo.

Legenda: P2_DB_iv = Reflexão em diário de bordo, relativa à sessão IV, do formando P2; P16_DB_iv = Reflexão em diário de bordo, relativa à sessão IV, do formando P16.

Associada à dificuldade de construção e utilização de instrumentos para avaliação da escrita, surgiu a dificuldade de definir os critérios que orientam essa avaliação, isto é, de clarificar que critérios são utilizados para conduzir esse processo, que foi percecionada em quase metade dos professores (11 em 19), tanto no $Q$, como nos DB e nas NC.

Por um lado, a afirmação explícita dessa dificuldade, nas reflexões em DB, de que o facto de seguirem um conjunto de critérios para avaliar dificulta esse processo, o que desde logo conduz à inferência de que podem não compreender verdadeiramente esses critérios (que aparentam não ser construídos pelos próprios), pelo que, consequentemente, o processo avaliativo estará comprometido. Também se registou que grande parte dos professores afirmou, aquando da resposta ao $Q$, que a definição de critérios de avaliação é um dos fatores que influencia o processo de avaliação, de que se infere, face aos resultados, que essa influência se pode materializar na dificuldade de o fazer. Com efeito, a definição de critérios para avaliação de textos é um aspeto que torna o processo complexo, pela dificuldade de se explicitar quais os aspetos a avaliar em cada dimensão que constitui o objeto texto (PINTO; PEREIRA, 2016).

Por outro, a dificuldade na explicitação dos critérios que são definidos e/ou de que modo são utilizados deixa transparecer a dificuldade que os professores podem sentir no dia a dia, para construir e utilizar critérios de avaliação que orientem o processo de EAA. Essa dificuldade parece estar naturalmente associada à dificuldade de 
construção e utilização de instrumentos de avaliação, já que a definição de critérios deve acompanhar o processo de avaliação, desde que se definam os objetivos a alcançar e que os instrumentos que permitam fazer a avaliação sejam coerentes com os critérios definidos.

A sobrevalorização e repetição dos mesmos focos de avaliação, como o respeito pelo tema do texto e das regras de ortografia, indicia essa dificuldade. Esses são os aspetos a que se deu maior relevo na avaliação/correção dos textos produzidos pelos alunos, o que pode revelar dificuldade de avaliar outras dimensões mais complexas do texto. Não obstante se tenham referido, com muito menor frequência, outros aspetos a avaliar, como a caligrafia, a pontuação, a diversidade lexical, a organização das ideias, a coesão e coerência e a estruturação do texto, não se explicita o modo como são usados. Nas reflexões desses professores também se verificou a referência a "critérios" como o "empenho", que estão de acordo com o preconizado no documento Critérios de avaliação do ensino básico (PORTUGAL, 2016, p. 4), ${ }^{7}$ em que se consideram elementos de avaliação do empenho, "a pontualidade, assiduidade, participação na aula, realização de trabalho de casa, do grupo, a Higiene corporal e apresentação". Note-se, contudo, que esses aspetos não dizem respeito à avaliação da produção escrita.

\section{CONSIDERAÇÕES FINAIS}

Os principais resultados emergentes quanto a conceções e práticas relatadas de avaliação da produção escrita indicam que o EAA da escrita não está totalmente ausente das aulas desse grupo de professores, mas a sua presença é ocasional e, muitas vezes, não programada. Os estudos nesse campo têm demonstrado que para avaliar a produção escrita é preciso, antes de mais, ensinar a produzir textos. Ora, de acordo com o que foi possível inferir, as práticas de ensino da escrita parecem não conduzir a uma aprendizagem bem-sucedida dessa competência, por razões de ordem diversa.

A ausência de avaliação ou a dificuldade de avaliar (d)a produção escrita estará, por certo, diretamente relacionada com o tipo de estratégias pedagógico-didáticas adotadas para ensinar os alunos a escrever. Porém algum défice de saberes dos professores sobre avaliação em geral (por exemplo, quanto às suas funções, à importância de dar feedback aos alunos, à falta de compreensão sobre o que são critérios e instrumentos de avaliação) também tem o seu papel nas conceções e práticas relatadas, no início da OF, sobre o objeto em estudo.

Por sua vez, as conceções de escrita que se identificaram têm implicações, inevitavelmente, no modo como os professores avaliam os textos dos alunos,

7 Documento policopiado não publicado, cedido pela Direcção do Ensino Básico de São Tomé e Príncipe. Esse documento pretende estabelecer parâmetros de avaliação dos alunos do $1^{\circ}$ e $2^{\circ} \mathrm{CEB}$, do curso diurno. 
pois quando existir avaliação ela incidirá sobretudo em aspetos como a ortografia, em detrimento de outros, que parecem ser ignorados, também no que respeita ao seu ensino.

Sendo a FC um espaço de excelência para o desenvolvimento profissional docente, defende-se que a aprendizagem continuada sobre possibilidades e estratégias de EAA da produção escrita, trabalhadas de modo contextualizado e atendendo às características dos intervenientes nesse processo, será potenciadora das mudanças positivas que se pretende alcançar. A análise de mudanças de conceções e práticas desse grupo de professores no que respeita ao EAA da produção escrita, numa fase seguinte, permitirá identificar os fatores potenciadores dessa mudança, que se crê estarem diretamente relacionados com estratégias adotadas no decorrer da OF, mas também com características individuais dos professores.

\section{REFERÊNCIAS}

BARDIN, Laurence. Análise de conteúdo. Lisboa: Edições 70, 2011.

BARREIRA, Carlos. Conceções e práticas de avaliação formativa e sua relação com os processos de ensino e aprendizagem. In: ORTIGÃO, Maria Isabel; FERNANDES, Domingos; PEREIRA, Talita; SANTOS, Leonor (ed.). Avaliar para aprender em Portugal e no Brasil: perspectivas teóricas e de desenvolvimento. Curitiba: CRV, 2019. p. 192-218.

BENNETT, Randy Elliot. Formative assessment: a critical review. Assessment in Education: Principles, Policy \& Practice, v. 18, n. 1, p. 5-25, 2011.

BOGDAN, Robert; BIKLEN, Sari. Investigação qualitativa em educação. Porto: Porto Editora, 1994.

BRANDÃO, Ana Carolina. A revisão textual na sala de aula: reflexões e possibilidades de ensino. In: LEAL, Telma; BRANDÃO, Ana Carolina (ed.). Produção de textos na escola: reflexões e práticas no ensino fundamental. Belo Horizonte: Autêntica, 2007. p. 119-134.

CARDOSO, Maria Inês. A relação com a escrita extra-escolar e escolar: um estudo no ensino básico. 2009. Tese (Doutorado em Didática) - Departamento de Didática e Tecnologia Educativa, Universidade de Aveiro, Aveiro, 2009.

CARVALHO, José Brandão. E agora... já se ensina a escrever? Uma reflexão sobre o impacto da investigação em didática da escrita nas práticas pedagógicas. In: TEIXEIRA, Madalena (ed.). Estudos da Língua Portuguesa: a união na diversidade. Santarém: Instituto Politécnico de Santarém - Escola Superior de Educação, 2019. p. 183-208.

COSTA, Nilza; LOPES, Betina; LUCAS, Margarida; CABRITA, Isabel; GONÇALVES, Manuela; DIOGO, Sara. Estudo de avaliação externa à reforma do ensino secundário de São Tomé e Príncipe (2009-2016): Relatório final. Aveiro: Universidade de Aveiro, 2017.

DOLZ, Joaquim; GAGNON, Roxane; DECANDIO, Fabrício. Produção escrita e dificuldades de aprendizagem. Campinas, SP: Mercado de Letras, 2010. 
FERNANDES, Domingos. Para um enquadramento teórico da avaliação formativa e da avaliação sumativa das aprendizagens escolares. In: ORTIGÃO, Maria Isabel; FERNANDES, Domingos; PEREIRA, Talita; SANTOS, Leonor (ed.). Avaliar para aprender em Portugal e no Brasil: perspectivas teóricas e de desenvolvimento. Curitiba: CRV, 2019. p. 139-164.

GONÇALVES, Maria de Lurdes. Desenvolvimento profissional e educação em línguas: potencialidades e constrangimentos em contexto escolar. 2011. Tese (Doutorado em Educação) - Departamento de Educação, Universidade de Aveiro, Aveiro, 2011.

GORGULHO, Ana Rita; COSTA, Nilza; TEIXEIRA, Madalena; SANTOS, Leonor. Ensino e avaliação da escrita no $2^{\circ}$ ciclo do ensino básico em São Tomé e Príncipe: enquadramento para uma oficina de formação. Indagatio Didactica, Aveiro, v. 10, n. 5, p. 87-109, 2018.

GORGULHO, Ana Rita; SANTOS, Leonor; COSTA, Nilza; SOUSA, Antónia Luísa. Formação contínua de professores de Português do ensino básico em São Tomé e Príncipe: uma proposta de oficina de formação sobre ensino e avaliação da escrita. Da Investigação às Práticas, Lisboa, v. 10, n. 1, p. 99-117, 2020. Disponível em: https://doi.org/10.25757/invep.v10i1.200. Acesso em: 29 out. 2020.

HADJI, Charles. A avaliação, regras do jogo: das intenções aos instrumentos. Porto: Porto, 1994.

HADJI, Charles. Avaliação desmistificada. Porto Alegre: Artmed, 2001.

LOURENÇO, Mónica; ANDRADE, Ana Isabel; MARTINS, Filomena. Formar para a diversidade linguística e cultural na educação infantil: possibilidades de construção de conhecimento profissional. Revista Internacional de Formação de Professores (RIFP), Itapetininga, SP, v. 2, n. 2, p. 76-99, abr./jun. 2017.

LUCIANO, Dilma; SÁ, Cristina. Transversalidade IX: reflexões sobre a escrita. Aveiro: UA Editora, 2019.

PEREIRA, Luísa Álvares; GRAÇA, Luciana. Contributos para a aprendizagem da escrita: dos princípios de ação à sequência de ensino como eixo da aprendizagem da produção de textos. Exedra, Aveiro, p. 195-208, 2015.

PINTO, Mariana; PEREIRA, Luísa Álvares. Escrever para aprender no ensino básico: das conceções dos professores... às práticas dos alunos. Revista Portuguesa de Educação, Braga, v. 29, n. 2, p. 109-139, 2016.

PORTUGAL. Ministério da Educação. Direç̧ão do Ensino Básico - DEB. Critérios de avaliação do ensino básico. Ano lectivo 2016/2017. São Tomé e Príncipe: Documento policopiado, não publicado, 2016.

ROLDÃO, Maria do Céu; FERRO, Nuno. O que é avaliar? Reconstrução de práticas e conceções de avaliação. Estudos em Avaliação Educacional, São Paulo, v. 26, n. 63, p. 570-594, set./dez. 2015.

SÃO TOMÉ E PRINCÍPE. Ministério da Educação e Cultura - MEC. Proposta curricular do ensino $\left(1^{a} a\right.$ $4^{a}$ classe). Revisão curricular dos programas para a $5^{\mathrm{a}}$ e a $6^{\mathrm{a}}$ classes do ensino básico da República Democrática de S. Tomé e Príncipe. São Tomé: MEC/Unicef, 2010. 
SÃO TOMÉ E PRINCÍPE. Ministério da Educação, Cultura e Formação - MECF. Carta de política educativa de São Tomé e Príncipe, Visão 2022. São Tomé e Príncipe: Ministério da Educação, Cultura e Formação, 2012.

SÃO TOMÉ E PRÍNCIPE. Lei n. 4/2018. Lei de Bases do Sistema Educativo. Diário da República, n. 14, I série, de 18 de fevereiro de 2019, p. 115-137.

SÃO TOMÉ E PRINCÍPE. Ministério da Educação, Cultura e Ciência - MECC. Programa Acelerar o Desempenho Educativo 2015-2018, [s.d.].

SÃO TOMÉ E PRÍNCIPE. Governo. Programa do XVII Governo Constitucional 2018 (documento policopiado). São Tomé, São Tomé e Príncipe, [s.d.].

SOUSA, Otília Costa e. Do trabalho de texto à reflexão linguística. In: SOUSA, Otília Costa e; CARDOSO, Adriana. (ed.). Desenvolver competências em língua: percursos didácticos. 2. ed. Lisboa: Edições Colibri/Centro Interdisciplinar de Estudos Educacionais, 2011. p. 111-143.

SUASSUNA, Lívia. Elementos para a prática da avaliação em língua portuguesa. Perspectiva, Florianópolis, v. 30, n. 3, p. 1125-1151, set./dez. 2012.

VIEIRA, Flávia. A experiência educativa como espaço de (trans)formação profissional. Lingvarvm Arena, Porto, v. 2, p. 9-26, 2011.

Recebido em: 29 JULHO 2020

Aprovado para publicação em: 14 AGOSTO 2020 